\title{
PD-1 blockade upregulate TIM-3 expression as a compensatory regulation of immune check point receptors in HNSCC TIL
}

\author{
Gulidanna Shayan ${ }^{1 *}$, Robert L Ferris ${ }^{2}$
}

From 30th Annual Meeting and Associated Programs of the Society for Immunotherapy of Cancer (SITC 2015) National Harbor, MD, USA. 4-8 November 2015

Programmed Death 1 (PD-1) and T cell Ig and mucin domain-3 protein (Tim-3) are immune check point receptors that are upregulated on tumor infiltrating lymphocytes (TIL) in tumor-bearing mice and humans. As anti-PD-1 single agent response rates are still relatively low (20\%) in HNC patients, it is important to learn how different inhibitory check point receptors work together to maintain the suppressive status of immune system. We observed that PD-1 and Tim-3 co-expression is associated with an exhausted phenotype of HNSCC TIL of patients, demonstrating the highest PD-1 levels in Tim-3 double positive TIL. We also observed that PD-1+/Tim-3+ TIL manifest dampened in Akt/p-S6 activation upon TCR stimulation, leading us to infer the potential for signaling cross-talk between PD-1 and Tim-3 downstream signaling pathways. Indeed, in freshly isolated HNSCC TIL, PD-1-/TIM-3+ $\mathrm{T}$ cells showed higher baseline expression of $\mathrm{p}-\mathrm{SHP}-2$ $(\mathrm{p}<0.01)$ which is triggered upon PD-1 ligation. In addition, PD-1 blockade using nivolumab of human HNSCC TIL led to upregulation of Tim-3 expression, suggesting a circuit of compensatory, cross-talk signaling and permitting escape from anti-PD-1 blockade during TCR stimulation. In a murine HNC tumor model, antiPD-1 treatment modestly suppressed tumor growth, but in TIL from persistent tumors in these mice, Tim-3 expression was dramatically upregulated after PD-1 blockade. Taken together, in response to PD-1 blockade, the most exhausted TIL appear to upregulate Tim-3 as a compensatory mechanism, supporting dual targeting, which may provide new therapeutic strategy for cancer immunotherapy.

University of Pittsburgh Hillman Cancer Center, Pittsburgh, PA, USA Full list of author information is available at the end of the article

\section{Authors' details}

${ }^{1}$ University of Pittsburgh Hillman Cancer Center, Pittsburgh, PA, USA.

${ }^{2}$ University of Pittsburgh Cancer Institute, Pittsburgh, PA, USA.

Published: 4 November 2015

doi:10.1186/2051-1426-3-S2-P196

Cite this article as: Shayan and Ferris: PD-1 blockade upregulate TIM-3 expression as a compensatory regulation of immune check point receptors in HNSCC TIL. Journal for ImmunoTherapy of Cancer 20153 (Suppl 2):P196.
Submit your next manuscript to BioMed Central and take full advantage of:

- Convenient online submission

- Thorough peer review

- No space constraints or color figure charges

- Immediate publication on acceptance

- Inclusion in PubMed, CAS, Scopus and Google Scholar

- Research which is freely available for redistribution

Submit your manuscript at www.biomedcentral.com/submit
() Biomed Central 


\section{Baseline expression of p-S6, SHP-2, p-SHP2 in PD-1+ Tim-3+ subsets of} TIL
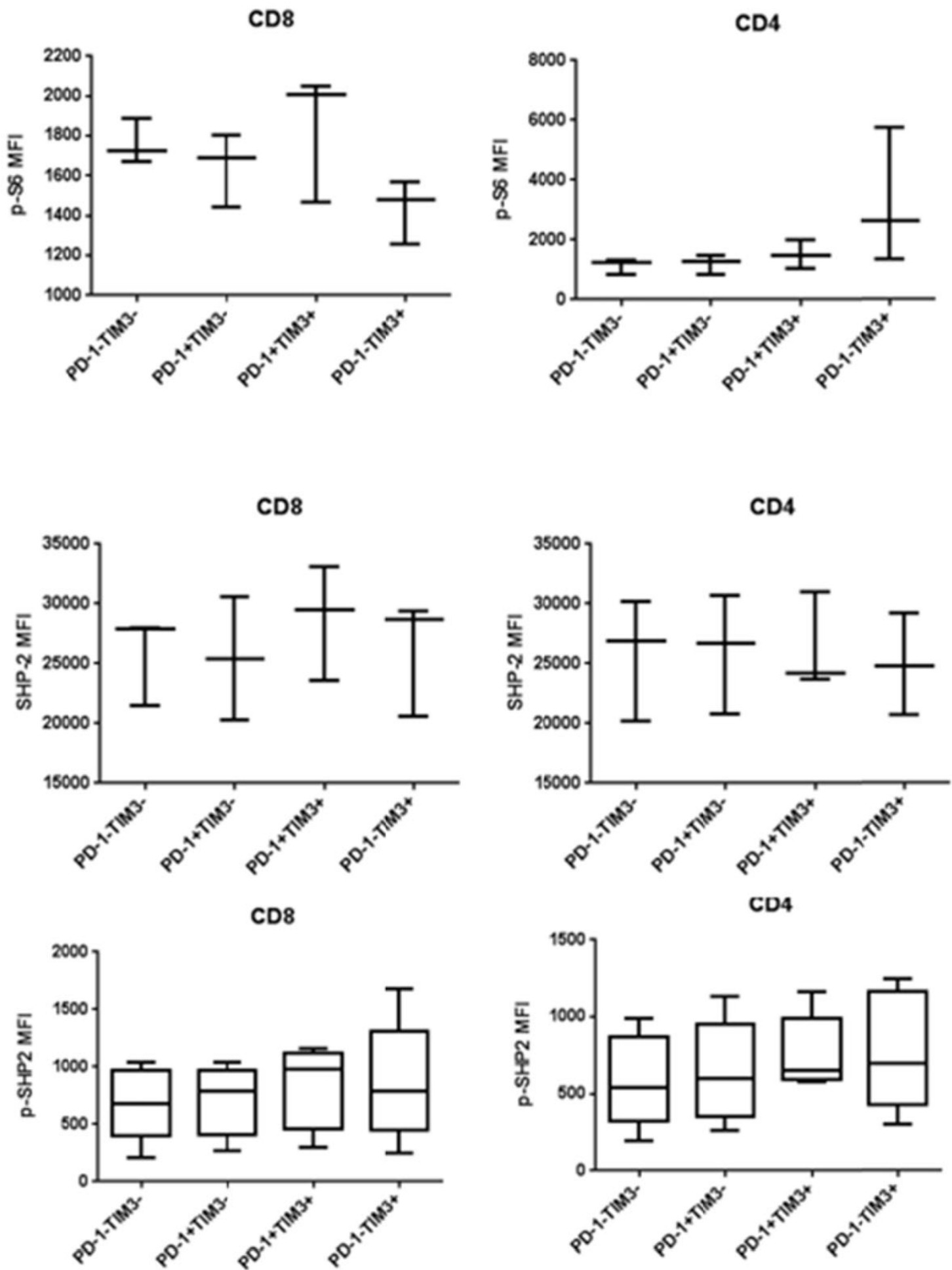

Figure 1 


\section{Baseline expression of p-S6, SHP-2, p-SHP2 in PD-1+ Tim-3+ subsets of} TIL.
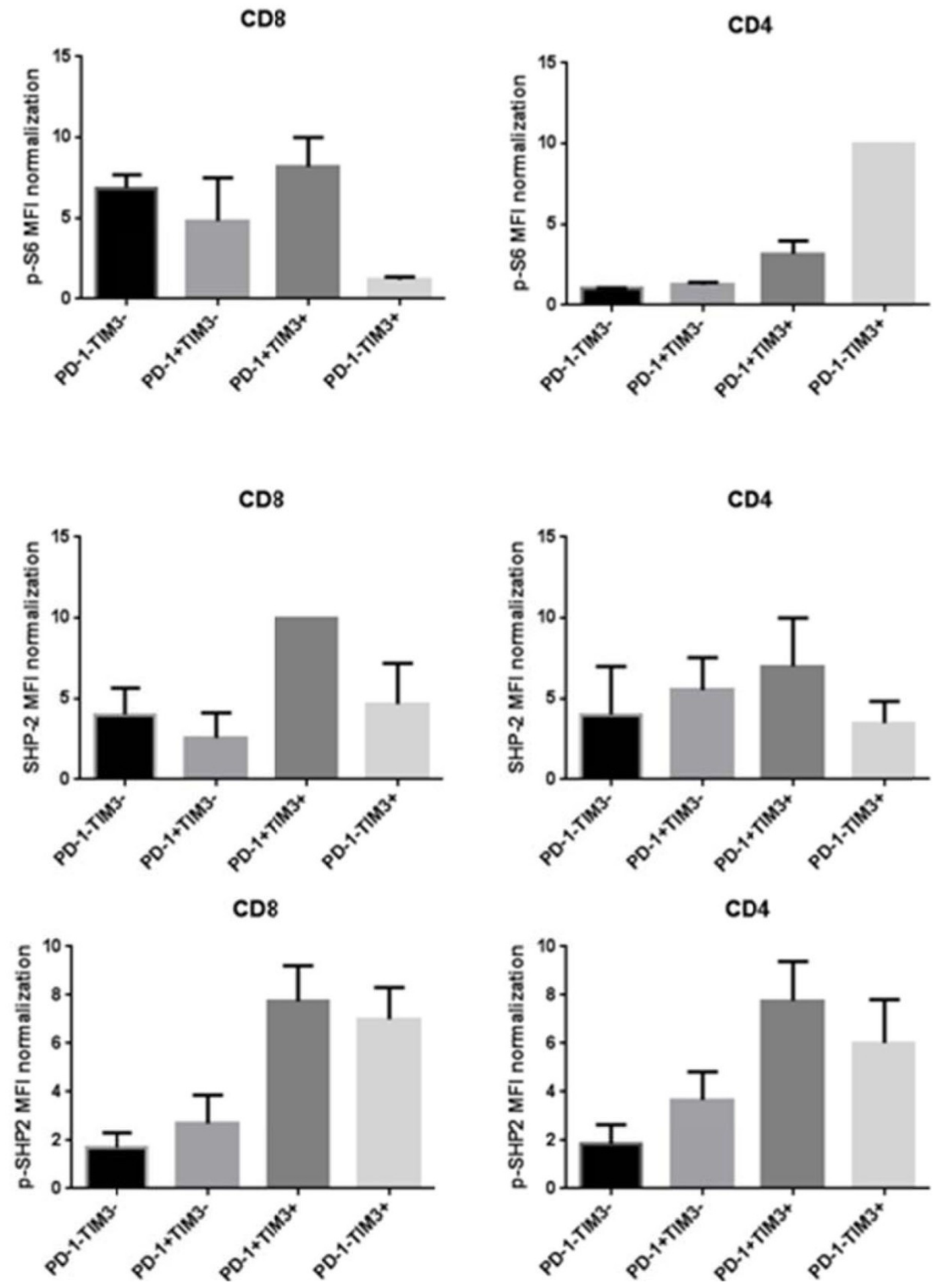

Figure 2 
Tim-3 expression level change after blocking of PD-1, CTLA-4 ex vivo in TIL
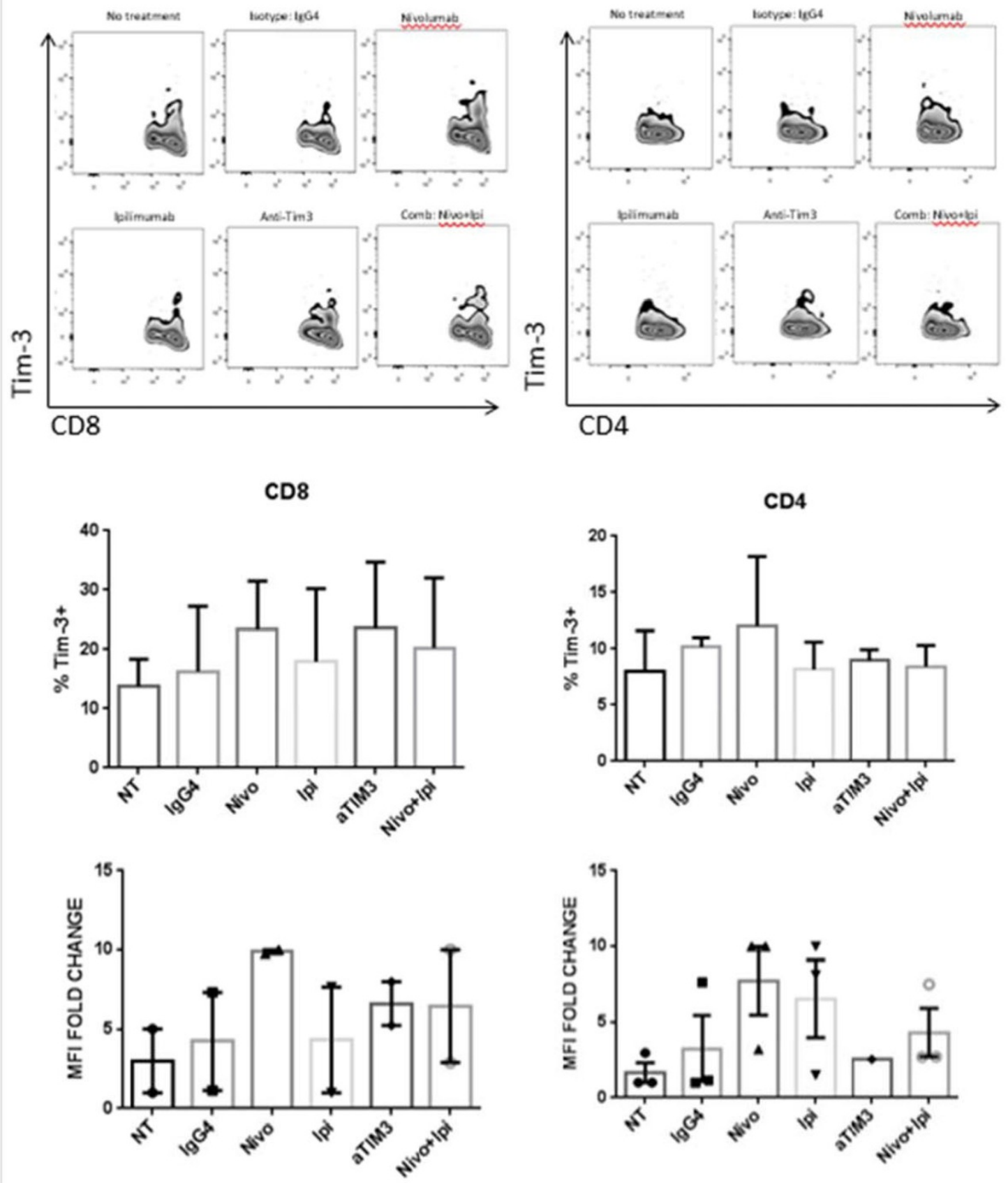


\section{Tim-3 expression level changes in anti-PD-1 treated mice TIL}

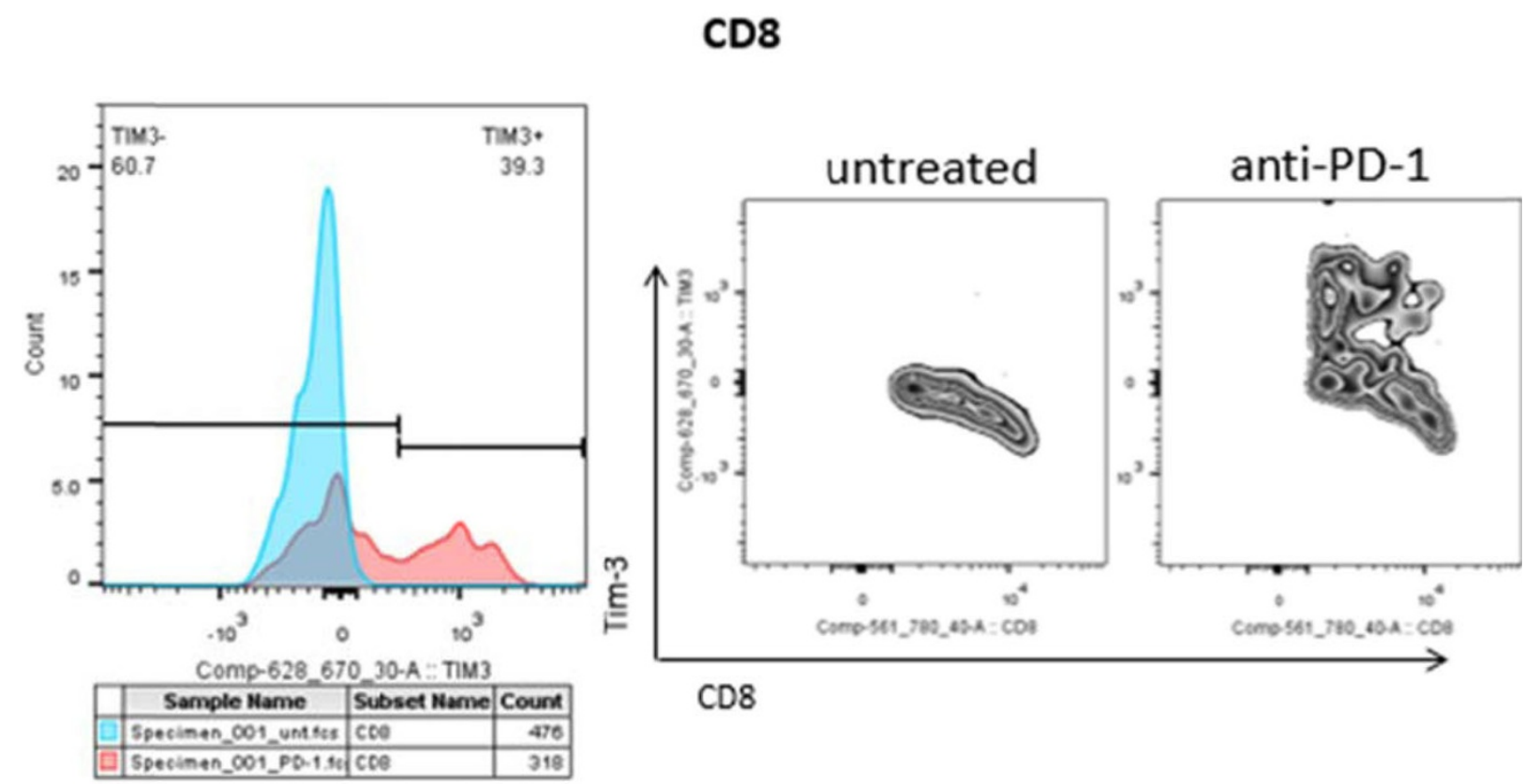

\section{CD4}
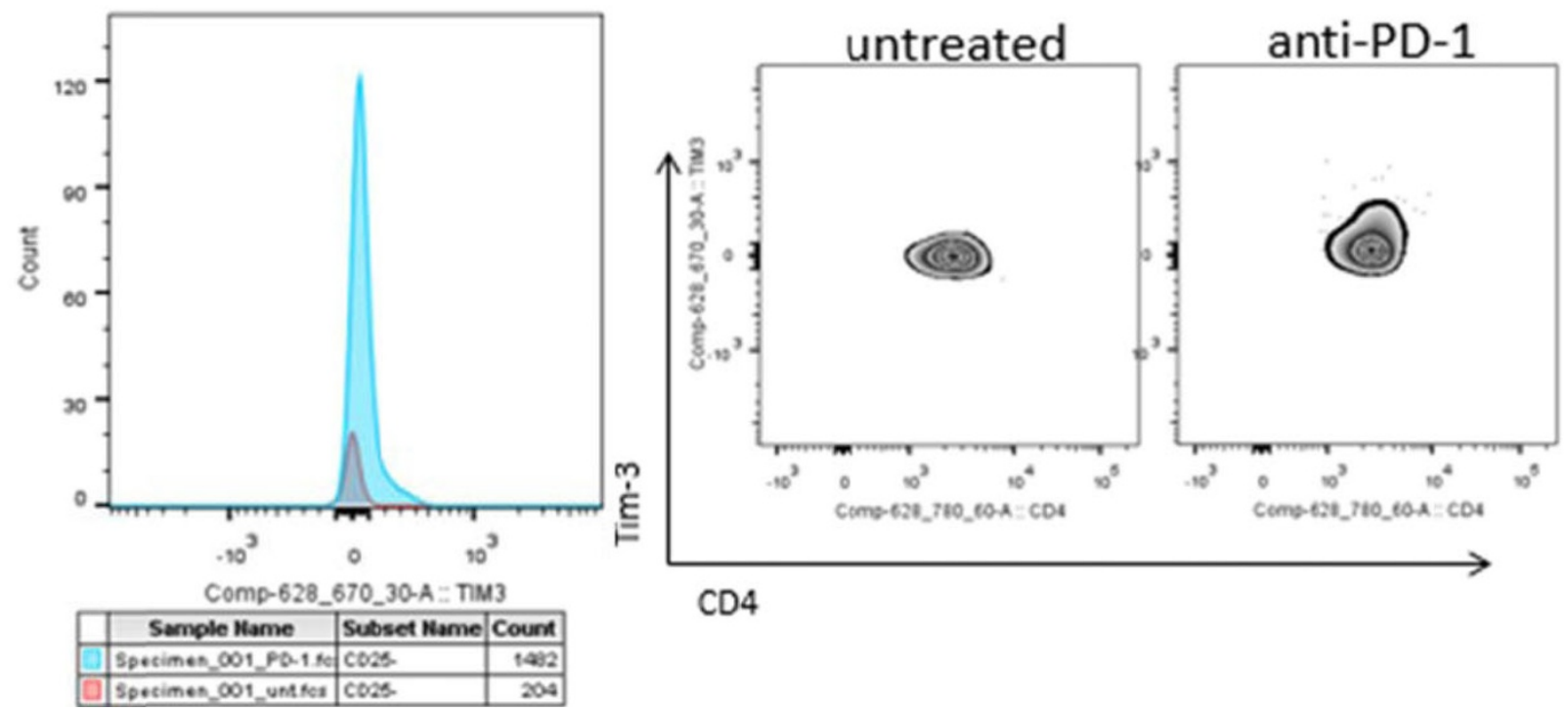

Figure 4 